\title{
Generating cadastral base for Kolathupalayam village in Tamil Nadu from high resolution LISS IV sensor data
}

\author{
A. Poornima, R. Jagadeeswaran*, Balaji Kannan and R. Sivasamy \\ Department of Remote Sensing and GIS, Tamil Nadu Agricultural University, Coimbatore- 641003 (Tamil Nadu), \\ INDIA \\ ${ }^{*}$ Corresponding author. E-mail: jagawaran@tnau.ac.in
}

Received: February 24, 2016; Revised received: August 4, 2016; Accepted: November 3, 2016

\begin{abstract}
In the present study an attempt was made to generate cadastral base from high resolution satellite image (LISS IV) and to integrate with land use land cover information. The digital cadastral map with survey number for Kolathupalayam village in Erode district of Tamil Nadu was scanned, digitized and parcels were extracted. Similarly parcels or field boundaries were digitized and extracted from satellite image and were statistically compared by area. The area obtained from both the source through digitization correlated well with a pearson correlation of 0.87 and it was significant at 5 per cent. Thus, the area comparisons from both methods are significant indicating boundaries of individual fields generated from satellite image matched well with the one generated from cadastral map. The cadastral base generated from satellite image was overlaid on the classified image (level III output) to identify and generate land cover information against each survey number. Thus, the LISS IV data can be used for the identification and extraction of cadastral boundaries with good accuracy.
\end{abstract}

Keywords: Cadastral base, High resolution data, Integration of LULC with cadastral base

\section{INTRODUCTION}

Remote Sensing integrated with Geographical Information System is an effective tool for the database generation, analysis and management of spatial data at different levels. The emerging new satellite technologies enabling earth observation at a spatial resolution of $1.0 \mathrm{~m}$ or less have brought revolutionary changes in the field of cadastral survey. The high resolution satellite imagery is showing its usefulness for cadastral surveys in terms of clear identification of parcel boundaries and other cultural features due to which traditional cadastre and land registration systems have been undergoing major changes worldwide (Rao et al., 2014). A cadastral map or village map is a map that shows the boundaries and ownership of land parcels, district name, unique identifying numbers for parcels, positions of existing structures, water body, road and power lines, common properties, adjoining and adjacent village names, selected boundary dimensions and references to prior maps. Cadastral information in the form of maps and records can be updated using high resolution satellite data of appropriate time or cropping season (Rao et al., 1996). Changing land use pattern and bifurcation of land holdings leads to reduction and or modification of parcel boundary and there is a need to update these changes on the existing maps which were generated long back. Jacobsen and Passini (2003) reported that effective tools to create cadastre maps are the modern high resolution satellite images, the digital photogrammetric methods for orthorectification with the use of ground control points (GCPs). Jayaprasad et al. (2007) utilized high resolution multispectral satellite image IKONOS for modification of village boundary, road, stream and field boundary using GCPs derived from DGPS survey and they validated the extracted field boundaries by comparing the area measured using total station survey and from Field Measurement Book.

Alkan and Marangoz (2009) applied fusion of high resolution satellite IKONOS and QuickBird imageries for making cadastral maps and extracted the parcel, building and road network objects from these datasets and compared with the existing digital cadastral maps and concluded that onscreen digitizing method process produces more close results as the real feature forms. Romuald and Svietlana (2011) attempted cadastral mapping of agricultural area in Tajikistan using high resolution satellite images (Quickbird \& IKONOS). Zahir Ali et al. (2012) developed and adopted an integrated approach for updating cadastral maps in Pakistan using satellite remote sensing data with participatory GIS technique. Jane Mithra and Suresh (2013) created various thematic layers and digital village cadastral information from the existing cadastral maps geo-referenced with high resolution satellite data viz., Cartosat-1 (PAN) and Resourcesat-1 LISS-IV fused imagery having $2.5 \mathrm{~m}$ spatial resolution at 1:10,000 scale. Govind Kumar et al. (2013) conducted study for updating geospatial information and quantification of 
the accuracy of the geo-referenced cadastral maps of a village in Andhra Pradesh using Google Earth imageries and high resolution satellite imageries. They reported that large area parcels have more accurate representation and less distortion than small area parcels and suggested that the methodology presented in this study is useful to update cadastral maps with low to medium accuracy. Rao et al. (2014) derived cadastral maps from ETS/GPS, High Resolution Satellite Images $(1 \mathrm{~m}$ and $0.5 \mathrm{~m})$ and compared the parcels extracted from various datasets using area, perimeter and position and observed that accuracy of parcel identification increases with increase in spatial resolution of the satellite imagery.

The data from the cadastral system provide an inventory and monitoring of the existing land use towards determining the sustainable future land use, its implementation and management. Cadastral map of ownership boundaries in association with natural resource database derived from high resolution satellite data (IRS LISS III PAN, and IRS LISS IV) provided information on current status of parcel wise land utilization. Tiede et al. (2007) updated the cadastral boundaries using the data obtained from land use land cover derived from SPOT-5 data. Frasera et al. (2008) investigated the applicability of utilising high-resolution satellite imagery (SPOT-5, IKONOS \& Quickbird) for providing geospatial data for Bhutan, principally to support topographic mapping, cadastral mapping and various local and regional planning functions. With this background knowledge the present investigation was carried out with the objectives of generating cadastral base from higher resolution satellite image, integrate with land use land cover details and to assess the quality of products generated from satellite image.

\section{MATERIALS AND METHODS}

The cadastral map of the study area viz., Kolathupalayam village, Erode district of Tamil Nadu was covered by three sheets. The cadastral maps have been scanned and the edge matching was performed using the Wise Image Pro 12.0 Software. The boundaries of two adjacent sheets were checked and corrected for proper mosaicking. Control points were taken from the Google Earth to give spatial reference for the cadastral map. The village map was georeferenced and rectified. The boundary of the village, road networks and the parcels were digitized from the cadastral map and the survey number was entered in geodatabase. The coverage is transformed into the new coordinate system, and projection parameters were added so as to make it compatible with other spatial database. The digitized cadastral map is converted in to coverage file to create the topology and the areas of land parcels were calculated. The multispectral ortho-rectified LISS-IV sensor imagery from Resourcesat-2 (Path/Row: 101/66) with a spatial resolution of $5.0 \mathrm{~m}$ acquired on September 11,
2014 was purchased from National Remote Sensing Centre (NRSC), Hyderabad, for the study. The boundary of Kolathupalayam village was extracted from cadastral map and overlaid on satellite image and the parcels and the road networks were digitized manually. The digitization was performed on-screen in ArcGIS 10.2 software and the detailed flowchart indicating the methodology is presented in Fig. 1.

Accuracy assessment and integration: The two modes of accuracy assessment, visual and numerical (quantitative) were attempted in the present study. The field boundaries or parcels extracted from cadastral map as well as satellite image were compared using area. The area accuracy was performed for digitized cadastral map and the digitized satellite image (LISS IV) and was correlated. About 20 parcels/polygons selected randomly for comparison and statistical agreement. The statistical analyses were performed using tTest and the results were analysed. The digitized cadastral map was superimposed over the classified Land use land cover map generated from LISS IV image and the land cover information was extracted for each survey number using the zonal statistics. The integrating process was performed in ArcGIS 10.2 software.

\section{RESULTS AND DISCUSSION}

The scanned cadastral map sheets were digitized to extract parcels and totally 580 parcels with survey numbers were generated. Similarly, the field boundaries which were visible on the LISS IV image were digitized and totally 571 field boundaries or polygons were generated from satellite image covering a village. The above exercise was performed by manual onscreen digitization. Randomly, 20 numbers of polygons generated from satellite image were selected and overlaid on digital cadastral map. The survey number wise area from cadastral map as well as from satellite image for the selected 20 polygons is presented in Table 1 . The comparison was performed considering area of the polygons. The size of polygon (parcels) on digital cadastral map varied from 1.14 ha to 8.47 ha with a mean and standard deviation of 3.28 and 2.25 ha, respectively. The polygon size on the digital layer generated from satellite image varied from 1.48 ha to 9.70 ha with a mean and standard deviation of 3.70 ha and 2.41 ha, respectively. The digitized cadastral boundaries generated (digitized) from both the sources overlaid on the LISS IV sensor image is shown in Fig. 2.

The above data is statistically analysed using paired $t$ test $(\mathrm{t}$ value $=2.09)$. The area obtained from both the source through digitization correlated well with a pearson correlation of 0.87 and it was significant at 5 per cent. Thus, the area of field parcels from both the methods are comparable indicating boundaries of individual fields generated from satellite image matched well with the one generated from cadastral map. However, the quality in terms of perimeter and positional 


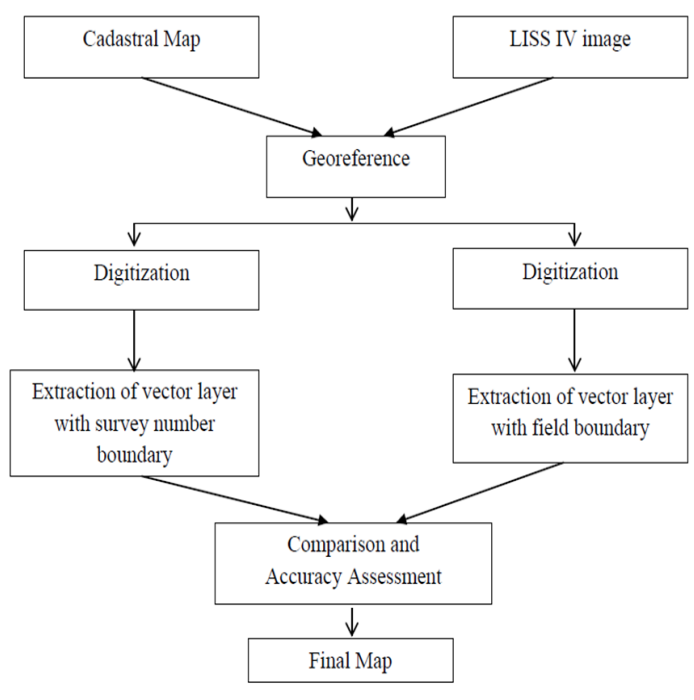

Fig. 1. Flow chart for cadastral base generation from satellite image.

Table 1. Comparison of digitized area from Cadastral map and Satellite image-LISS IV (By Random Selection of Polygons).

\begin{tabular}{cccc}
\hline S.N. & Survey No. & $\begin{array}{c}\text { Area from ca- } \\
\text { dastral map } \\
\text { (ha) }\end{array}$ & $\begin{array}{c}\text { Area from sat- } \\
\text { ellite image (ha) }\end{array}$ \\
\hline 1 & 14 & 7.87 & 7.01 \\
2 & 60 & 4.37 & 4.46 \\
3 & 95 & 1.21 & 1.56 \\
4 & 110 & 2.18 & 2.10 \\
5 & 159 & 2.44 & 2.20 \\
6 & 164 & 4.57 & 7.00 \\
7 & 171 & 6.77 & 6.44 \\
8 & 194 & 2.38 & 2.88 \\
9 & 200 & 2.31 & 2.40 \\
10 & 245 & 1.93 & 1.53 \\
11 & 275 & 3.25 & 3.62 \\
12 & 306 & 8.47 & 9.71 \\
13 & 357 & 1.68 & 1.62 \\
14 & 407 & 5.35 & 5.46 \\
15 & 420 & 1.54 & 1.89 \\
16 & 459 & 3.47 & 2.88 \\
17 & 468 & 1.89 & 2.30 \\
18 & 494 & 1.40 & 1.48 \\
19 & 524 & 1.30 & 5.87 \\
20 & 548 & 1.14 & 1.52 \\
& Minimum & 1.14 & 1.48 \\
& Maximum & 8.47 & 9.71 \\
& Mean & 3.28 & 3.70 \\
& Standard & & \\
& deviation & 2.25 & 2.41 \\
& $\mathrm{t}$ value: 2.09 (non-significant) \\
\hline
\end{tabular}

accuracy were not tested in this study. Cadastral or village maps are the large scale base maps available for analysis and mapping at micro level. Updating cadastral boundaries and associated features are essential for better governance. Generally the field boundaries or parcels extracted from various data sets can be com-

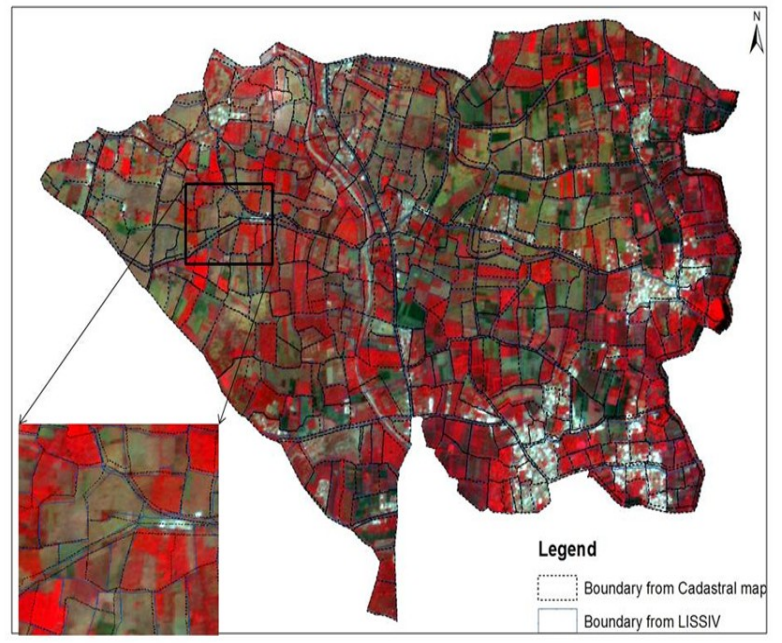

Fig. 2. The parcel boundaries extracted from cadastral map and satellite overlaid on LISSIV image for Kolathupalayam village in Tamil Nadu.

pared using their attributes viz., area, perimeter and position. In this study area was considered for comparison. Tiede et al. (2007) updated the cadastral boundaries using the data obtained from land use land cover derived from SPOT-5 data. Frasera et al. (2008) investigated the applicability of utilising highresolution satellite imagery (SPOT-5, IKONOS \& Quickbird) for providing geospatial data to support cadastral mapping. Jane Mithra and Suresh (2013) created various thematic layers and digital village cadastral information from the existing cadastral maps geo-referenced with high resolution satellite data viz., Cartosat-1 (PAN) and Resourcesat-1 LISS-IV fused imagery having $2.5 \mathrm{~m}$ spatial resolution. Rao et al. (2014) derived cadastral maps from High Resolution Satellite Images $(1 \mathrm{~m}$ and $0.5 \mathrm{~m})$ and compared the parcels extracted from various datasets using area, perimeter and position and reported that accuracy of parcel identification increases with increase in spatial resolution. Thus, suggesting the cadastral base generated from LISS IV data helps in updating the cadastral boundary periodically. Similar work was carried out by Rao et al. (1996) using LISS III data and reported that the boundaries of cadastral maps matched well with image detail with respect to various features and agricultural fields. Zahir Ali and Shafiq Ahmed (2013) made a similar attempt to extract parcel boundaries from high resolution Quickbird imagery and reported that this method of extraction is effective and time saving.

Integration of cadastral base with land use / land cover information: In the present work the digital cadastral map was integrated with classified output (classified at Level-III category) to generate survey number wise land use land cover data. Integrating cadastral boundary/field boundary generated either from cadastral map or from satellite image with land use / 
land cover information helps to generate survey number wise land cover and land use pattern for the current season besides updating boundaries and their periodical subdivisions. The season and crop reports of government departments are available for districts and if this reports are generated for individual parcel, it would help the government agencies to have accurate estimation of crop area and yield in near real time. Morley (1977) and Rao et al. (1996) suggested that overlaying satellite imagery on cadastral map can improve the details of the thematic maps as well as action plan maps. It also helps in the monitoring of changes that can be measured at survey number or parcel level.

\section{Conclusion}

The present study clearly indicates that multispectral high resolution LISS IV data can be used to generate or update cadastral base with 87 per cent accuracy. And also the cadastral boundaries generated from LISS IV satellite data can be integrated well with current land use land cover information to extract parcel wise data for planning, updation and management.

\section{REFERENCES}

Alkan, M. and Marangoz, M.A. (2009). Creating cadastral maps in rural and urban areas of using high resolution satellite imagery. Applied Geoinformatics for Society and Environment-Stuttgart University of Applied Sciences, 89-95

Frasera Clive, Dorji Tsheringb and Armin Gruenc. (2008). High-resolution satellite imagery for spatial information generation in Bhutan. The International Archives of the Photogrammetry, Remote Sensing and Spatial Information Sciences. Vol. XXXVII. Part B6a. Beijing 2008

Govind Kumar, V.V., VenkataReddy, K. and Deva Pratap. (2013). Updation of cadastral maps using high resolution remotely sensed data. International Journal of Engineering and Advanced Technology, 2(4): 50-54

Jacobsen, K. and Passini, R. (2003). Accuracy of digital orthophotos from High Resolution Space imagery. Con- ference: High Resolution Mapping from Space, Hannover

Jane Mithra, S., and Suresh, P. (2013). Creation of digital village cadastral and thematic information for integrated decentralized planning in Kerala. Kerala State Remote Sensing \& Environment Centre, Thiruvananthapuram, India, Indian Cartographer vol., XXXIII. 20-25

Jayaprasad, P.A., Nadeema, R., Ghosha , S.K. Pathana and Ajaia, S., Kaliappanb , R., Vidhyab and M. Shanmugam. (2007). Updation and metrology of cadastre and village boundary using high-resolution satellite data. J. Geometrics, 1(2): 71-75

Morley, L.W. (1977). Surveys for Development (ed. Nossin, J.J.), Elsievier, Amsterdam.

Rao, D.P., Navalgund, R.R. and Krishna Murthy, Y.V.N. (1996). Cadastral applications using IRS-1C data-Some case studies. Current Science, 70 (7): 624-628

Rao, S.S., Sharma, J.R., Rajasekhar, S.S., Rao, D.S.P., Arepalli, A., Arora, V., Kuldeep, R.P., Singh and M. Kanaparthi. (2014). Assessing Usefulness of High-Resolution Satellite Imagery (HRSI) for Re-Survey of Cadastral Maps. ISPRS Annals of the Photogrammetry, Remote Sensing and Spatial Information Sciences, ISPRS Technical Commission VIII Symposium, Hyderabad, India, Vol. II-8: 133143

Romuald Kaczynski and Svietlana Marahina. (2011). Cadastral Mapping of Agricultural Areas in Tajikistan. International Conference: Environmental Engineering, Vilnius, Lithuania :1344-1347

Tiede, D., M.S. Moeller, S. Lang and D. Hoelbling. (2007). Adapting, Splitting and Merging Cadastral boundaries according to homogenous LULC types derived from Spot 5 data. International Archives of Photogrammetry, Remote Sensing and Spatial Information Sciences, 36: 99-104

Zahir Ali and Shafiq Ahmed (2013). Extracting Parcel Boundaries from Satellite Imagery for a Land Information System. IEEE: 79-81

Zahir Ali, Arbind Tuladhar and Jaap Zevenbergen. (2012). An integrated approach for updating cadastral maps in Pakistan using satellite remote sensing data. International J. Applied Earth Observations and Geoinformation, 18: 386-398 